\title{
BMJ Open Cognitive impairment in a primary healthcare population: a cross-sectional study on the island of Crete, Greece
}

\begin{abstract}
Antonios Konstantinos Bertsias (1) , ${ }^{1}$ Ioanna Tsiligianni, ${ }^{1}$ Sophia Papadakis, ${ }^{1,2}$ Ioannis Zaganas, ${ }^{3}$ George Duijker, ${ }^{1}$ Emmanouil K Symvoulakis, ${ }^{1}$ Polyvios Papadokostakis, ${ }^{1}$ Kornilia Makri, ${ }^{1}$ Eliza latraki, ${ }^{1}$ Chariklia Tziraki, ${ }^{4}$ Maria Basta, ${ }^{5}$ Simeon Panagiotakis, ${ }^{6}$ Dimitrios Boumpas, ${ }^{7}$ Joanna Moschandreas, ${ }^{8}$ Panagiotis Simos, ${ }^{5}$ Alexandros Vgontzas, ${ }^{5}$ Christos Lionis, ${ }^{1}$ and on behalf of the Cretan Primary Health Care Ageing Network
\end{abstract}

To cite: Bertsias AK, Tsiligianni I, Papadakis S, et al. Cognitive impairment in a primary healthcare population: a cross-sectional study on the island of Crete, Greece. BMJ Open 2020;10:e035551. doi:10.1136/ bmjopen-2019-035551

- Prepublication history and additional material for this paper are available online. To view these files, please visit the journal online (http://dx.doi. org/10.1136/bmjopen-2019035551).

Received 05 November 2019 Revised 21 April 2020 Accepted 16 July 2020

D Check for updates

(c) Author(s) (or their employer(s)) 2020. Re-use permitted under CC BY-NC. No commercial re-use. See rights and permissions. Published by BMJ.

For numbered affiliations see end of article.

Correspondence to Mr Antonios Konstantinos Bertsias;

antonisbertsias@yahoo.gr

\section{ABSTRACT}

Objectives Cognitive impairment is known to have a significant impact on the quality of life of individuals and their caregivers, yet it is often underdiagnosed. The objective of this study is to assess the extent of cognitive impairment among elders visiting primary healthcare (PHC) practice settings, to explore associated risk factors and discuss current care challenges for PHC providers.

Design A cross-sectional study was conducted between March 2013 and May 2014.

Setting Fourteen PHC units located in rural and urban areas of the Heraklion district in Crete, Greece.

Participants Consecutive visitors aged at least 60 years attending selected PHC practices.

Primary and secondary outcome measures The MiniMental State Examination (MMSE) was used to indicate cognitive status. Associations of low MMSE scores ( $\leq 23 / 24$, adjusted for education level) with 12 sociodemographic factors, comorbidities and lifestyle factors were assessed.

Results A total of $3140 \mathrm{PHC}$ patients met inclusion criteria ( $43.2 \%$ male; mean age $73.7 \pm 7.8$ years). The average MMSE score was $26.0 \pm 3.8 ; 26.7 \pm 3.5$ in male and $25.4 \pm 3.9$ in female participants $(p<0.0001)$. Low MMSE scores were detected in $20.2 \%$ of participants; $25.9 \%$ for females vs $12.8 \%$ for males; $p<0.0001$. Female gender (adjusted OR $(\mathrm{AOR})=2.72 ; 95 \% \mathrm{Cl} 2.31$ to 3.47), age (AOR=1.11; 95\% $\mathrm{Cl} 1.10$ to 1.13 ), having received only primary or no formal education (AOR=2.87; 95\% Cl 2.26 to 3.65), alcohol intake ( $A 0 R=1.19 ; 95 \% \mathrm{Cl} 1.03$ to 1.37), reporting one or more sleep complaints (AOR 1.63; 95\% $\mathrm{Cl} 1.14$ to 2.32), dyslipidaemia ( $\mathrm{AOR}=0.80 ; 95 \% \mathrm{Cl} 0.65$ to 0.98 ) and history of depression (AOR=1.90; $95 \% \mathrm{Cl} 1.43$ to 2.52) were associated with low MMSE scores.

Conclusions This study identified a relatively high prevalence of low MMSE scores among persons attending PHC practices in a southern European community setting and associations with several known risk factors.

\section{INTRODUCTION}

With the gradual increase in population longevity, chronic conditions have become more prevalent, with cognitive disorders

\section{Strengths and limitations of this study}

- This is the first study assessing the burden of cognitive impairment in a primary care setting in Greece.

- The sample size was relatively large (3140 individuals) and recruited from both rural and urban areas.

- Poor performance on cognitive tasks such as MiniMental State Examination could be due factors other than cognitive decline. Comprehensive neuropsychological evaluation is necessary in order to establish clinical diagnosis.

- Since the majority of participants visited the selected primary healthcare for prescription renewal, the study population may include fewer healthy older adults than those living in the community.

being among the most common. ${ }^{1}{ }^{2}$ In the elderly, measurable decline in cognitive abilities, including memory, can be caused by several reversible and non-reversible conditions, while mild cognitive impairment (MCI) and dementia represent the most common conditions. ${ }^{3}{ }^{4}$ Lacking a disease-modifying drug treatment, early detection and management of risk factors remains a key strategy in the reduction of the rate of MCI and dementia. ${ }^{5}$ Several modifiable risk-factors for cognitive impairment as well as for the onset and progression of MCI and dementia in particular, have been identified in the literature. Some appear to be gender-specific, yet they have not been studied extensively. ${ }^{5}$ 7-13

According to Alzheimer Europe, it is estimated that the total population prevalence of dementia in Greece is $1.77 \%$, slightly exceeding the EU-28 average of $1.55 \% .{ }^{14} \mathrm{~A}$ more recent population study estimated the prevalence of dementia in those aged 65 years or older at $5 \%$, with $75 \%$ of the cases being attributed to Alzheimer's disease. ${ }^{15}$ In 
regard to MCI, the estimated prevalence in populationbased studies ranges from $10 \%$ to $20 \%$ in persons older than 65 years of age. ${ }^{41617}$ Little is known about the extent and epidemiology of cognitive impairment in primary healthcare (PHC) settings in Greece, where the impact of the Greek financial crisis since 2010 on population health and the burden to healthcare services is well documented. ${ }^{18-20}$ In order to address this challenge, healthcare reforms were implemented with a focus on primary care, disease prevention and health promotion by establishing several new urban primary care units throughout the country. ${ }^{21}$

In this context, a multi-disciplinary research network was established at the Faculty of Medicine, University of Crete, Greece including researchers and practitioners from various medical disciplines (Thales MNSADMultidisciplinary Network for the Study of Alzheimer's disease) to study the magnitude of this health problem and discuss the care challenges for the healthcare services. ${ }^{22}$ The present report uses baseline data from the PHC team with the aim to inform healthcare providers and policy-makers regarding the extent of cognitive impairment in the PHC population, and associations with demographic and clinical risk factors, as judged by the Mini-Mental State Examination (MMSE). Specific objectives were the following:

- To report the extent of elders with low scores on a widely adopted screening instrument for dementia (MMSE) among those served by primary care centres in the prefecture of Heraklion Crete, Greece.

- To identify key modifiable clinical, lifestyle and demographic variables associated with cognitive impairment and report on probable between-gender variations.

\section{METHODS \\ Setting}

A cross-sectional study was conducted between March 2013 and May 2014 in well-defined PHC settings in the prefecture of Heraklion on the island of Crete, Greece. Eligible units were staffed by general practitioners (GPs) who were members of a previously established PHC research network coordinated by the Clinic of Social and Family Medicine, Faculty of Medicine, University of Crete. Fourteen PHC units (12 public and 2 private) from a total of 22 public units in the district of Heraklion participated in the study: Eleven public PHC practices (two organised health centres and nine satellite practices) were located in rural and semi-urban areas, serving a total population of 100800 residents; and three urban PHC units (one public and two private) in the city of Heraklion, serving a total population of 174000 residents (online supplementary table 1).

\section{Population and inclusion criteria}

Eligible participants were persons aged 60 years or older, who were consecutive visitors in the participating PHC units, for any reason other than urgent care. Acutely ill patients or those requiring urgent referral to a secondary healthcare centre were excluded. Established diagnosis of dementia or MCI was not an exclusion factor. Eligible participants were invited by the trained GPs to participate in the study. All interviews were conducted by trained nurses. Participants' companions were asked to provide information in cases where participants had difficulty providing adequate information. Participant responses on clinically relevant questions were later verified by their GP. Further description of our population is reported elsewhere. $^{22}$

\section{Measurements}

A structured and pre-tested questionnaire was used to collect information from patients and caregivers on the following variables: socio-demographics (age, gender, place of residency, marital status, number of children, number of housemates, current/former employment status, number of rooms in the house, living situation, level and years of formal education received), health and lifestyle habits (smoking and alcohol consumption, number of days/week patient walked and total time of walking), self-reported night sleep duration (in hours) and presence of insomnia symptoms (difficulty falling asleep or maintaining sleep (DMS), and early morning awakening), ${ }^{23}$ and presence of chronic non-communicable, neurological or psychiatric illnesses and prescribed medication. Chronic conditions were self-reported by patients, or reported by their caregivers and cross-validated by their GPs against the patient's electronic health record. Participants were also administered the Greek version of the $\mathrm{MMSE}^{24}$ to assess general cognitive ability and the Barthel index of Activities of Daily Living (ADL) ${ }^{25} 26$ was completed as part of the interview with the participant or caregiver. Finally, anthropometric measurements were measures by the interviewer (weight, height, waist circumference).

\section{Definitions}

The Greek version of MMSE has been validated, and cutoff scores of 23/24 were found to have high specificity, sensitivity and positive predictive value ${ }^{27}$ for detecting dementia in accordance with the original validation study of the English version. ${ }^{24}$ In view, however, of the very high percentage of persons who had attained $\leq 6$ years of formal education in the present, largely rural, sample $(81.7 \%)$, we used education-adjusted MMSE cutoffs of $\leq 24 / 30$ (for those with $>6$ years of formal education) and $\leq 23 / 30$ (for those with $\leq 6$ years) to classify participants in the low MMSE group. ${ }^{28}$ A Barthel index score of 90/90 was used to indicate complete independence in ADL. ${ }^{26}$ Prolonged sleep was defined as reporting $\geq 9$ hours of sleep on a given day. ${ }^{29}{ }^{30}$ Obese were considered participants with a body mass index (BMI) $\geq 30 \mathrm{~kg} / \mathrm{m}^{2}$.

\section{Data collection}

All interviews were performed during PHC working hours by specially trained GPs and nurses. Data were initially recorded on paper and then transferred to the Clinic 
of Social and Family Medicine at the University of Crete where consistency checks and data entry and storage was performed.

\section{Sample size estimation}

The objective of the overall multi-disciplinary study (Thales MNSAD) ${ }^{22}$ was to enrol a minimum of 250 persons meeting formal Diagnostic and Statistical Manual of Mental Disorders (DSM) IV criteria for dementia. Assuming an 8\% (95\% CI $7.1 \%$ to $9.0 \%$ ) prevalence of any type of dementia ${ }^{31}$ among PHC visitors over 60 years of age, a minimum sample size of 3200 participants was estimated.

\section{Statistical analysis}

Demographic and other characteristics were summarised using descriptive statistics. Between-gender univariate comparisons were made using Pearson's $\chi^{2}$ test of independence (for categorical variables) and independent samples t-test (for continuous variables). The variability of estimated cognitive impairment was calculated using robust standard errors clustering by PHC unit. ${ }^{32}$

Logistic regression models were used to assess unadjusted associations between participant characteristics and probable cognitive impairment (low MMSE scores). The patient characteristics were: age (centred), gender (male, female), level of education (none, primary, secondary or greater), presence of obesity (yes, no), current smoker (yes/no), alcohol intake per month (measured in grams), reports at least one sleep complaint (yes/no), hypertension (yes, no), type 2 diabetes (yes, no), dyslipidaemia (yes, no), depression (yes, no) and traumatic brain injury (yes, no). Multilevel logistic regression models were also performed in order to obtain ORs adjusted for probable risk factors (that had been pre-selected based on the literature). ${ }^{5}$ The multilevel models included 12 predictor variables in addition to PHC unitspecific random effects. The variance inflation factor was computed in order to assess potential multicollinearity. The operation of the participating PHC units (public vs private) was used as a level-2 variable.

All participants with complete data on age, gender and MMSE scores were included in the analysis and any further missing data were handled by pairwise deletion. The level of significance was set to 5\%, IBM SPSS V.21 and STATA V.11 were used to conduct the analyses.

\section{Patient and public involvement}

There was no patient and public involvement.

\section{RESULTS}

\section{Participants}

A total of 3471 individuals were invited to participate of whom $271(7.8 \%)$ declined participation. The main reasons for non-participation were lack of time for the interview $(80 \%)$ and unwillingness to participate in research $(20 \%)$. In the majority of the 3200 conducted interviews ( $\mathrm{n}=2698$, $84.0 \%$ ), a caregiver/companion was present. On checking for duplicate entries and data consistency, 60 entries were removed from the database resulting in a total of 3140 entries included in the analysis.

\section{General description of the population}

Details regarding socio-demographic and other socioeconomic characteristics of participants are presented in table 1. The mean age of participants was $73.7(\mathrm{SD}=7.8)$ years, with most respondents being female $(\mathrm{n}=1785,56.8 \%)$. The majority $(n=2845,90.6 \%)$ of individuals visited the selected $\mathrm{PHC}$ practices for prescription renewal.

Overall, $391(12.5 \%)$ participants were current tobacco users and 1368 (43.7\%) reported current alcohol consumption. Smoking and alcohol consumption were more frequent among men, as shown in table 2. Average BMI was higher among females than males $\left(30.7 \mathrm{~kg} / \mathrm{m}^{2}(\mathrm{SD}=5.4)\right.$ vs 28.8 $\mathrm{kg} / \mathrm{m}^{2}(\mathrm{SD}=4.1)$, respectively; $\left.\mathrm{p}<0.0001\right)$. Nearly half of the participants $(\mathrm{n}=1285 ; 49.4 \%)$ reported walking for at least 10 min daily and averaging $6.3(\mathrm{SD}=1.8)$ hours of sleep per night. Sleep-related problems were reported by 2056 (67.1\%) participants and were more frequently reported in females than males $(\mathrm{p}<0.0001$ across symptoms $)$. Of the 3140 participants, $2594(82.7 \%)$ were found to be fully independent in activities of daily living as measured by the Barthel index.

The most frequently reported chronic conditions (see table 3) were hypertension ( $\mathrm{n}=2140 ; 68.2 \%)$, dyslipidaemia $(n=1427 ; 45.4 \%)$, type 2 diabetes $(n=786 ; 25.0 \%)$ and benign prostate hyperplasia ( $n=335 ; 24.8 \%$ in males) . Significant gender differences in the frequency of several chronic conditions were noted.

\section{The extent of cognitive impairment (according to MMSE scores)}

The average MMSE score was 26.0 ( $\mathrm{SD}=3.8)$ and was significantly higher in males than females (26.7 vs 25.4; $95 \%$ CI for the difference: 1.00 to $1.54 ; \mathrm{p}<0.0001)$. Low MMSE scores ( $\leq 23 / 24$, depending on education) were detected in 631 (20.2\%, $95 \%$ CI $13.6 \%$ to $27.4 \%)$ participants, $459(25.9 \%, 95 \%$ CI $17.6 \%$ to $33.9 \%)$ females and $172(12.8 \%, 95 \%$ CI $8.4 \%$ to $18.1 \%)$ males; $\mathrm{p}<0.0001)$. As can be seen in figure 1, the proportion of females with low MMSE scores appeared consistently higher than that of males across all age groups. The frequency of low MMSE scores was $8.6 \%$ (95\% CI $5.4 \%$ to $11.5 \%$ ) in participants aged $60-70$ years $(11.2 \%, 95 \%$ CI $7.7 \%$ to $14.5 \%$ in females vs $4.4 \%-95 \%$ CI $1.7 \%$ to $7.0 \%$ in males; $\mathrm{p}<0.00001$ ) and $44.2 \%$ (95\% CI $27.5 \%$ to $60.9 \%$ ) in those aged 86 years or older $(58.7 \%$, 95\% CI $30.7 \%$ to $86.6 \%$ in females vs $31.7 \%, 95 \%$ CI $22.2 \%$ to $41.0 \%$ in males; $\mathrm{p}<0.00001)$.

\section{Associations between MMSE scores and selected fixed and modifiable risk factors}

There were several significant associations between fixed and modifiable risk factors and the odds of having low MMSE scores (table 4, online supplementary table 2). In regard to non-modifiable factors, the odds of having a low MMSE score increased with age (adjusted OR (AOR) $1.11 ; 95 \%$ CI 1.09 to $1.13 ; \mathrm{p}<0.0001$ ) and with low levels (none or primary) of education in both genders (AOR 
Table 1 Socio-demographic characteristics of participants and between-gender comparisons



*8 missing values.

†12 missing values.

$\ddagger 14$ missing values.

$\S 28$ missing values.

ๆ0 missing values.

3.03; 95\% CI 2.32 to 4.00 in females, AOR 2.56; $95 \%$ CI 1.67 to 3.77 in males; $\mathrm{p}<0.0001$ for both).

Regarding modifiable risk factors, reporting at least one sleep complaint increased the odds of having a low MMSE score in females both in unadjusted and adjusted analyses (AOR 1.54; 95\% CI 1.12 to 2.09; $\mathrm{p}=0.007$; but not in males when adjusting for the other factors $(\mathrm{p}=0.715)$. The presence of type 2 diabetes was not associated with low MMSE scores, neither overall nor in males and females separately (see table 4 and online supplementary table 2). The presence of hypertension was also not associated with low MMSE scores in either males or females, after adjusting for the other factors, while dyslipidaemia was associated with a lower odds of having low MMSE scores in females but not males, both in unadjusted and adjusted analyses (AOR $0.70 ; 95 \%$ CI 0.55 to 0.92 ; $\mathrm{p}=0.010$ ). Monthly alcohol intake (in $\mathrm{kg}$ ) was associated with increased odds of low MMSE scores only in males (AOR 1.25; 95\% CI from 1.01 to 1.45 ; $\mathrm{p}=0.014$ ). Depression increased the odds of having low MMSE scores in both genders (AOR 1.74; 95\% CI 1.24 to 2.42; $\mathrm{p}=0.001$ in females; AOR 2.61; 95\% CI 1.41 to 4.55 ; $\mathrm{p}<0.0001$ in males). Traumatic brain injury increased the adjusted odds of having low MMSE scores in males only (AOR $3.60 ; 95 \%$ CI 1.41 to 9.16 ; $\mathrm{p}=0.007$ ).

\section{DISCUSSION}

\section{Main findings}

The present report documents a significant extent of cognitive impairment, as indicated by low MMSE scores, among persons older than 60 years visiting communitybased primary care settings in a Southern European island. Specifically, as many as one in five persons across genders (and twice as many women than men) were identified as having probable cognitive impairment. Furthermore, certain modifiable risk factors were associated with low MMSE scores, some of which were common to both genders and some gender-specific. These factors included lifestyle habits, such as alcohol consumption, sleep disturbances and specific chronic illnesses such as depression and dyslipidaemia which are frequently treated in the context of PHC consultation.

\section{Discussion in the light of the literature}

Despite the older average age of male compared to female participants, the proportion of those with a low MMSE 
Table 2 Health habits, anthropometric characteristics and reported sleep problems of participants and between-gender comparisons

\begin{tabular}{|c|c|c|c|c|}
\hline & $\begin{array}{l}\text { Overall } \\
(n=3140)\end{array}$ & $\begin{array}{l}\text { Females } \\
(n=1785)\end{array}$ & $\begin{array}{l}\text { Males } \\
(n=1355)\end{array}$ & $P$ value \\
\hline Current smoker, $\mathrm{n}(\%)^{*}$ & $391(12.5)$ & $130(7.3)$ & 261 (19.3) & $<0.0001$ \\
\hline Ever smoker, n (\%)† & $1164(37.3)$ & $221(12.4)$ & $943(70.0)$ & $<0.0001$ \\
\hline Current alcohol consumer, $\mathrm{n}(\%) \ddagger$ & $1368(43.7)$ & $447(25.1)$ & $921(68.2)$ & $<0.0001$ \\
\hline Ever alcohol consumer, $\mathrm{n}(\%) \S$ & $1634(52.3)$ & $547(30.7)$ & $1087(80.6)$ & $<0.0001$ \\
\hline Social alcohol consumer, $\mathrm{n}(\%) \S$ & $832(26.6)$ & $248(13.6)$ & $585(44.2)$ & $<0.0001$ \\
\hline Daily alcohol consumer, $\mathrm{n}(\%) \emptyset$ & $840(26.8)$ & $170(9.4)$ & $670(50.6)$ & $<0.0001$ \\
\hline BMI $\left(\mathrm{kg} / \mathrm{m}^{2}\right)$, mean (SD) & $29.9(5.0)$ & $30.7(5.4)$ & $28.8(4.1)$ & $<0.0001$ \\
\hline Walks daily for $>10 \mathrm{~min}, \mathrm{n}(\%)^{\star \star}$ & $1285(49.4)$ & $590(40.6)$ & $695(60.5)$ & $<0.0001$ \\
\hline Hours of sleep/night, mean (SD) & $6.3(1.8)$ & $6.0(1.8)$ & $6.6(1.8)$ & $<0.0001$ \\
\hline Prolonged sleep ( $\geq 9$ hours), n (\%) & $226(7.3)$ & $100(5.6)$ & $126(9.7)$ & $<0.0001$ \\
\hline 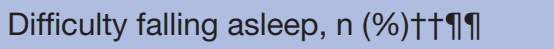 & $1371(44.0)$ & $944(53.1)$ & $427(31.8)$ & $<0.0001$ \\
\hline Difficulty maintaining sleep, $n(\%)^{\star \star \star} \neq \ddagger$ & $1700(54.3)$ & $1060(59.5)$ & $640(47.3)$ & $<0.0001$ \\
\hline Early awakening, $\mathrm{n}(\%) \S \S † \dagger †$ & $1093(35.1)$ & 733 (41.3) & 361 (26.9) & $<0.0001$ \\
\hline At least one sleep complaint, $\mathrm{n}(\%)$ & $2056(67.1)$ & $1279(73.0)$ & $777(46.8)$ & $<0.0001$ \\
\hline $\begin{array}{l}\text { Fully independent in activities of daily } \\
\text { living, } n(\%) \ddagger \ddagger \ddagger\end{array}$ & $2594(82.7)$ & $1427(80.1)$ & $1167(86.3)$ & $<0.0001$ \\
\hline
\end{tabular}

*9 missing values.

$\dagger 12$ missing values.

$\ddagger 8$ missing values.

$\S 13$ missing values.

१3 missing values.

**539 missing values.

††18 missing values.

$\ddagger \ddagger 4$ missing values.

$\S \S 43$ missing values.

१ๆ21 missing values.

***7 missing values.

†††24 missing values.

$\ddagger \ddagger \ddagger 5$ missing values (Barthel index).

BMI, body mass index.

score (which indicates presence of probable MCI and/or dementia) was almost double among females. This finding is consistent with other studies which have also reported lower average MMSE scores in females compared to males. ${ }^{1333} 34$ In addition to lower MMSE scores, morbidity was greater in females attending PHC units compared to males, with a higher number of chronic conditions more frequently reported by females.

In regard to the selected modifiable life-style risk factors and co-morbidities, the present results indicate that their impact on probable cognitive impairment varies by gender, a fact that is also previously reported in the literature. ${ }^{2425}$ In the gender-specific analysis, self-reported sleep problems emerged as a significant correlate of low MMSE performance in women. In a recent French study the reported number of sleep complaints as well as the DMS were associated cognitive decline according to MMSE scores. ${ }^{35}$ Similar patterns were identified in the KORA (Cooperative Health Research in the Augsburg Region) study where cognitive decline was more pronounced in individuals with DMS. ${ }^{23}$ The MrOS (Outcomes of Sleep Disorders in Older Men) Sleep study, found waking after sleep onset and the number of long-wake episodes to be associated with a 1.4-fold to 1.5 -fold increase in odds of clinically significant cognitive decline. ${ }^{29}$ A more detailed analysis regarding specific insomnia-type symptoms and cognitive impairment in the present study population has been reported elsewhere and has indicated a strong gender effect. ${ }^{36}$ As regards alcohol consumption, our study reported similar results with another study that indicated that excessive alcohol consumption in men ( $\geq 36 \mathrm{~g} /$ day) was associated with faster cognitive decline compared with light to moderate alcohol consumption. ${ }^{37}$

This present study indicated a positive association between presence of dyslipidaemia and higher MMSE scores in females but a lack of association in men. This finding deserves some explanation, and it may reflect a favourable impact of long-term use of statins. Recent studies have indicated that statins could decrease the risk of dementia, Alzheimer's disease and improve cognitive 
Table 3 Frequency of most common chronic conditions for the entire population and by gender



*1 missing value.

†No missing values.

$\ddagger 2$ missing values.

$\S 3$ missing values.

$\mathrm{BPH}$, benign prostate hyperplasia; CHD, coronary heart disease; COPD, chronic obstructive pulmonary disease; GORD, gastro-oesophageal reflux disease.

impairment in some cases, yet the reduction in disease risk can vary across statin molecules, sex and race/ ethnicity. ${ }^{38}$ In our sample, the majority of participants diagnosed with dyslipidaemia $(\sim 70 \%)$ were being treated with statins, so it was hard to disentangle the relative impact of dyslipidaemia of statin use.$^{50-42}$ Furthermore, the cross-sectional nature of this work did not allow us to draw causal conclusions. Our results did not indicate statistically significant associations between obesity, type 2 diabetes or hypertension and cognitive impairment,

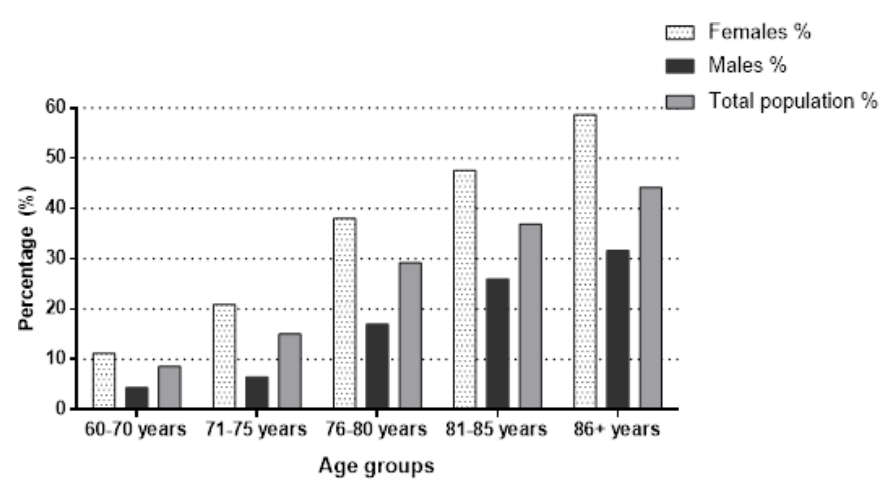

Figure 1 Proportion of participants with probable cognitive impairment according to Mini-Mental Scale Examination scores by gender and age group. based on the multivariable analysis, in contrast with several previous reports. ${ }^{53}$ This picture could reflect other factors with a potential effect in the participants that they have not assessed in this study such as a traditional life-style or adherence to Mediterranean diet. ${ }^{44} \mathrm{On}$ the other hand, a positive association between depression and probable cognitive impairment was identified in both genders and between history of traumatic brain injury and probable cognitive impairment in males. Similar findings have also been reported in the literature. ${ }^{45-48}$

\section{Strengths and limitations}

To our knowledge, this is the first study assessing the extent of probable cognitive impairment in a PHC setting in Greece. Furthermore, the study sample size is relatively large and although it did not employ a door-todoor approach or a randomly selected population sample (selection of the PHC facilities having been based on their being staffed by members of a PHC research network), the use of consecutive patients can provide a relatively accurate description of the characteristics of PHC visitors within a well-defined area. As most public PHC units were located in rural and semi-urban areas, generalisation may be limited. In addition, information from the data may have been lost due to the dichotomisation of 
Table 4 Odds of probable cognitive impairment according to MMSE scores and associations with the selected demographic and clinical variables in the total sample and by gender

\begin{tabular}{|c|c|c|c|}
\hline & Overall & Females & Males \\
\hline Independent variables & OR (95\% Cl; p value) & OR (95\% Cl; p value) & OR (95\% Cl; p value) \\
\hline Gender (female) & 2.72 (2.31 to $3.47 ; p<0.0001)$ & - & - \\
\hline Level of education (sprimary) & 2.87 (2.26 to $3.65 ; p<0.0001)$ & 3.18 (2.36 to $4.29 ; p<0.0001)$ & $2.45(1.62$ to 3,$71 ; p<0.0001)$ \\
\hline Obese (yes) & $0.92(0.74$ to $1.14 ; p=0.447)$ & $0.89(0.96$ to $1.15 ; p=0.387)$ & 1.02 (0.70 to $1.51 ; p=0.903)$ \\
\hline Monthly alcohol intake (kg) & $1.19(1.03$ to $1.365 ; p=0.024)$ & $0.99(0.99$ to $1.06 ; p=0.937)$ & $1.25(1.010$ to $1.45 ; p=0.014)$ \\
\hline At least one sleep complaint (yes) & 1.63 (1.15 to $2.32 ; p=0.006)$ & 1.54 (1.12 to $2.09 ; p=0.007)$ & $1.08(0.71$ to 1,$64 ; p=0.715)$ \\
\hline Hypertension (yes) & $0.92(0.73$ to $1.61 ; p=0.475)$ & $0.89(0.67$ to $1.20 ; p=0.482)$ & $0.94(0.63$ to $1.41 ; p=0.777)$ \\
\hline Type 2 diabetes (yes) & 0.92 (0.73 to $1.18 ; p=0.548)$ & $0.93(0.69$ to $1.25 ; p=0.645)$ & 0.91 (0.58 to $1.40 ; p=0.656)$ \\
\hline Dyslipidaemia (yes) & 0.80 (0.65 to $0.98 ; p=0.038)$ & $0.70(0.55$ to $0.92 ; p=0.010)$ & $1.01(0.68$ to $1.49 ; p=0.986)$ \\
\hline $\begin{array}{l}\text { PHC unit operation (public vs } \\
\text { private) }\end{array}$ & 0.59 (0.29 to $2.66 ; p=0.489)$ & $0.60(0.11$ to $3.39 ; p=0.564)$ & $0.57(0.19$ to $1.68 ; p=0.311)$ \\
\hline
\end{tabular}

Mean VIF $=1.09$. All variables had VIF scores $<1.5$

${ }^{*} \mathrm{AOR}$ for the unit increase above the mean.

MMSE, mini-mental state examination; PHC, primary healthcare; VIF, variance inflation factor.

the MMSE scores prior to model fitting. In our study the MMSE was used, however, for the detection of probable cognitive impairment. At the cut-off point that we used, the MMSE is characterised by high sensitivity and relatively low specificity as a screening tool for dementia: poor performance on cognitive tools such as MMSE could be due to other factors. ${ }^{46} 49$ Thus, a comprehensive neuropsychological evaluation is necessary in order to establish clinical diagnosis. However, analysis of data from sub-group of the present sample defined by the corresponding DSM-IV criteria 303 of 344 (88\%) participants with MMSE scores $<24$ were diagnosed as having either MCI or dementia. ${ }^{22}$ In addition to the above, in our study, we have excluded from recruitment patients visiting PHC facilities for an emergency, thus we have excluded delirium or other acute causes that may have an effect on cognition. As the cut-offs used in our study have previously been validated for detecting severe MCI or dementia, ${ }^{27}$ we are somewhat confident that cognitive impairment as judged by education-adjusted low MMSE in our population corresponds roughly to severe CI or dementia.

Although associations between MMSE scores and specific chronic conditions and characteristics were identified, the cross-sectional nature of the study does not support causal links. Additionally, it should be noted that the majority of participants visited the selected PHC for prescription renewal, most likely because they suffered from a chronic condition. In this manner, our population may not include healthy older adults, as well as persons suffering from debilitating conditions that are typically treated in acute care settings and would not typically visit
PHC units in Greece. Finally, it should be noted that our study was powered to estimate the prevalence of cognitive impairment and not for the associations observed using the multivariable regression models.

\section{Implications for practice and research}

The findings of this cross-sectional study reveal a significant extent of probable cognitive impairment in a primary care setting. Given the progressive nature of cognitive impairment in older persons, the results of this study emphasise the need for improved screening in PHC. PHC practitioners may require additional training in terms of the need, screening procedures and management practices related to cognitive impairment and associated comorbidities. In this respect, we have already reported that as many as $60 \%$ of patients with dementia have not received a diagnosis before seeing a specialist. ${ }^{22}$ Moreover, specific conditions such as depression could be used as an alarm signal to investigate cognitive impairment.

In Greece, a recent healthcare reform with a focus on prevention has just been applied with the establishment of local PHC units in urban centres. In the context of the new national plan for dementia that has been prepared by the Ministry of Health, screening for cognitive impairment could be included among the tasks of the family physicians who serve these new PHC units.

\section{CONCLUSIONS}

This cross-sectional PHC-based study provides new information on the prevalence of probable cognitive impairment in a mainly rural Southern European primary care 
population aged 60 years and older. Our findings suggest that cognitive impairment is a challenge for the PHC services in a country currently undergoing reform in the governance and role of primary care services.

\section{Author affiliations}

${ }^{1}$ Clinic of Social and Family Medicine, University of Crete Faculty of Medicine, Heraklion, Greece

${ }^{2}$ Division of Prevention and Rehabilitation, University of Ottawa Heart Institute, Ottawa, Ontario, Canada

${ }^{3}$ Department of Neurology, University of Crete Faculty of Medicine, Heraklion, Greece

${ }^{4}$ Gerontological Data Center, Hebrew University of Jerusalem, Jerusalem, Jerusalem, Israel

${ }^{5}$ Department of Psychiatry, University of Crete Faculty of Medicine, Heraklion, Greece

${ }^{6}$ Department of Internal Medicine, University of Crete Faculty of Medicine, Heraklion, Greece

${ }^{7}$ Department of Internal Medicine, National and Kapodistrian University of Athens Faculty of Medicine, Athens, Greece

${ }^{8}$ Department of Social Medicine, University of Crete Faculty of Medicine, Heraklion, Greece

Acknowledgements We would like to thank Myron Galenianos and Cynhtia Manasaki for their valuable contribution to the coordination of the project. We would also like to thank Dr Nikolaos Scarmeas for the overall assistance in the design and evaluation of the project. Finally, we would like to thank the following study nurses who played an important role in recruitment of participants and conducted the interviews and tests: Sofia Marinaki, Marina Lyroni, Maria Maniou, Georgia Fragkiadaki, Maria Titaki and Katerina Almpantaki.

Collaborators The Cretan Primary Health Care Ageing Network consists of the following GPs: Dr Theodoros Vasilopoulos from the Health Centre of Agia Varvara; Dr Eva Ladoukaki from the Health Centre of Charakas; Drs Nikolaos Tsakountakis, Rodanthi Pateli, Eirini Kalogridaki and Aggeliki Vasilaki from the Health Centre of Kastelli; Drs loanna Stefanaki and Emmanouil Papamastorakis from the Health Centre of Ano Viannos; Dimitroula Prokopiadou from the Health Centre of Arkalochori and the private primary care practitioner Dr Eleni Klouva.

Contributors AKB: performed data entry, statistical analysis and drafted the first version of the manuscript, CT, DB, CL and AV: conceived the idea of the project, IT: contributed to drafting and revision of the manuscript, SP: supervised the data analysis and contributed to drafting and revision of the manuscript, IZ: contributed to the project coordination and drafting a revision of the manuscript, GD: was the PHC study-team coordinator and contributed to drafting the manuscript, EKS, PP, $\mathrm{KM}, \mathrm{El}, \mathrm{CT}, \mathrm{MB}, \mathrm{SP}$ and DB: contributed to drafting the manuscript and reviewed the manuscript, JM: contributed to drafting and revision of the manuscript and advised on data analysis, PS: contributed to drafting and revision of the manuscript, AV: was the Pl of the project and contributed to drafting and revision of the manuscript, $\mathrm{CL}$ : contributed to drafting and revision of the manuscript and was supervisor and coordinator of the PHC team. All authors have reviewed manuscript prior to submission.

Funding This project was supported by a grant from the European Union (European Social Fund - ESF) and Greek national funds through the Operational Programme "Education and Lifelong Learning" of the National Strategic Reference Framework (NSRF)-Research Funding Programme: THALES entitled "UOC-Multidisciplinary network for the study of Alzheimer's Disease" (Grant Code: MIS 377299).

Competing interests None declared.

Patient consent for publication Not required.

Ethics approval The study was approved by the Bioethics Committee of the University Hospital of Heraklion (protocol number: 13541, 20.11.2010). All eligible persons or their caregivers were informed both verbally and through a patient/ caregiver information sheet about the study by their GP and provided written consent if they agreed to participate. For patients unable to provide it, informed consent was provided by their caregivers.

Provenance and peer review Not commissioned; externally peer reviewed.

Data availability statement Data may be obtained from a third party and are not publicly available. Data and materials for this study are available from the authors upon reasonable request. Due to restrictions stated in our ethical approvals data are not available on public data repositories.

Supplemental material This content has been supplied by the author(s). It has not been vetted by BMJ Publishing Group Limited (BMJ) and may not have been peer-reviewed. Any opinions or recommendations discussed are solely those of the author(s) and are not endorsed by BMJ. BMJ disclaims all liability and responsibility arising from any reliance placed on the content. Where the content includes any translated material, BMJ does not warrant the accuracy and reliability of the translations (including but not limited to local regulations, clinical guidelines, terminology, drug names and drug dosages), and is not responsible for any error and/or omissions arising from translation and adaptation or otherwise.

Open access This is an open access article distributed in accordance with the Creative Commons Attribution Non Commercial (CC BY-NC 4.0) license, which permits others to distribute, remix, adapt, build upon this work non-commercially, and license their derivative works on different terms, provided the original work is properly cited, appropriate credit is given, any changes made indicated, and the use is non-commercial. See: http://creativecommons.org/licenses/by-nc/4.0/.

ORCID iD

Antonios Konstantinos Bertsias http://orcid.org/0000-0003-3515-2488

\section{REFERENCES}

1 World Alzheimer Report. Alzheimer's disease international, 2015.

2 Prince MU, Prince MU, Wimo A, et al. World Alzheimer Report 2015 The Global Impact of Dementia: An analysis of prevalence, incidence, cost and trends, 2015.

3 Lipnicki DM, Sachdev PS, Crawford J, et al. Risk factors for late-life cognitive decline and variation with age and sex in the Sydney memory and ageing study. PLoS One 2013;8:e65841.

4 Alzheimer's association. Mild cognitive impairment. Available: https:// www.alz.org/

5 Baumgart M, Snyder HM, Carrillo MC, et al. Summary of the evidence on modifiable risk factors for cognitive decline and dementia: a population-based perspective. Alzheimers Dement 2015;11:718-26.

6 Livingston G, Sommerlad A, Orgeta V, et al. Dementia prevention, intervention, and care. Lancet 2017;390:2673-734.

7 Legdeur N, Heymans MW, Comijs HC, et al. Age dependency of risk factors for cognitive decline. BMC Geriatr 2018;18:187.

8 Ren L, Zheng Y, Wu L, et al. Investigation of the prevalence of cognitive impairment and its risk factors within the elderly population in Shanghai, China. Sci Rep 2018;8:3575.

9 Xiu S, Liao Q, Sun L, et al. Risk factors for cognitive impairment in older people with diabetes: a community-based study. Ther Adv Endocrinol Metab 2019;10:2042018819836640.

10 Ren L, Bai L, Wu Y, et al. Prevalence of and risk factors for cognitive impairment among elderly without Cardio- and cerebrovascular diseases: a population-based study in rural China. Front Aging Neurosci 2018;10:62.

11 Lyu J, Kim H-Y. Gender-Specific incidence and predictors of cognitive impairment among older Koreans: findings from a 6-year prospective cohort study. Psychiatry Investig 2016;13:473-9.

$12 \mathrm{Kim} \mathrm{S}$, Kim MJ, Kim S, et al. Gender differences in risk factors for transition from mild cognitive impairment to Alzheimer's disease: a CREDOS study. Compr Psychiatry 2015;62:114-22.

13 Pradier C, Sakarovitch C, Le Duff F, et al. The mini mental state examination at the time of Alzheimer's disease and related disorders diagnosis, according to age, education, gender and place of residence: a cross-sectional study among the French national Alzheimer database. PLoS One 2014;9:e103630.

14 Alzheimer-Europe. Alzheimer-Europe, 2016. Available: http://www. alzheimer-europe.org/Policy-in-Practice2/Country-comparisons/Theprevalence-of-dementia-in-Europe [Accessed 08 Feb 2016]

15 Kosmidis MH, Vlachos GS, Anastasiou CA, et al. Dementia prevalence in Greece: the Hellenic longitudinal investigation of aging and diet (HELIAD). Alzheimer Dis Assoc Disord 2018;32:232-9.

16 Petersen RC. Mild cognitive impairment. N Engl J Med Overseas Ed 2011;364:2227-34.

17 Di Carlo A, Lamassa M, Baldereschi M, et al. CIND and MCI in the Italian elderly: frequency, vascular risk factors, progression to dementia. Neurology 2007;68:1909-16.

18 Kondilis E, Giannakopoulos S, Gavana M, et al. Economic crisis, restrictive policies, and the population's health and health care: the Greek case. Am J Public Health 2013;103:973-9. 
19 Kentikelenis A, Karanikolos M, Papanicolas I, et al. Health effects of financial crisis: omens of a Greek tragedy. The Lancet 2011;378:1457-8.

20 Tsiligianni IG, Papadokostakis P, Prokopiadou D, et al. Impact of the financial crisis on adherence to treatment of a rural population in Crete, Greece. Qual Prim Care 2014;22:238-44.

$21 \mathrm{WHO}$. Greek health reform: opening of new primary health care units. WHO, 2017.

22 Zaganas IV, Simos P, Basta M, et al. The Cretan aging cohort: cohort description and burden of dementia and mild cognitive impairment. Am J Alzheimers Dis Other Demen 2019;34:23-33.

23 Johar $\mathrm{H}$, Kawan R, Emeny RT, et al. Impaired sleep predicts cognitive decline in old people: findings from the prospective KorA age study. Sleep 2016;39:217-26.

24 Folstein MF, Folstein SE, McHugh PR. "Mini-mental state". A practical method for grading the cognitive state of patients for the clinician. J Psychiatr Res 1975;12:189-98.

25 Mahoney FI, Barthel DW. Functional evaluation: the BARTHEL index. Md State Med J 1965;14:61-5.

26 Theofanidis D. Validation of international stroke scales for use by nurses in Greek settings. Top Stroke Rehabil 2017;24:214-21.

27 Fountoulakis KN, Tsolaki M, Chantzi H, et al. Mini mental state examination (MMSE): a validation study in Greece. Am J Alzheimers Dis Other Demen 2000;15:342-5.

28 Wilson RS, Hebert LE, Scherr PA, et al. Educational attainment and cognitive decline in old age. Neurology 2009;72:460-5.

29 Blackwell T, Yaffe K, Ancoli-Israel S, et al. Association of sleep characteristics and cognition in older community-dwelling men: the MROS sleep study. Sleep 2011;34:1347-56.

30 Westwood AJ, Beiser A, Jain N, et al. Prolonged sleep duration as a marker of early neurodegeneration predicting incident dementia. Neurology 2017;88:1172-9.

31 Tsolaki M, Fountoulakis C, Pavlopoulos I, et al. Prevalence and incidence of Alzheimers disease and other dementing disorders in Pylea, Greece. Am J Alzheimers Dis 1999;14:138-48.

32 Kirkwood BR, Sterne JAC, Kirkwood BR. Essential medical statistics. Malden Mass, Blackwell Science, 2003.

33 Laws KR, Irvine K, Gale TM. Sex differences in cognitive impairment in Alzheimer's disease. World J Psychiatry 2016;6:54-65.

34 Artero S, Ancelin M-L, Portet F, et al. Risk profiles for mild cognitive impairment and progression to dementia are gender specific. $J$ Neurol Neurosurg Psychiatry 2008;79:979-84.
35 Jaussent I, Bouyer J, Ancelin M-L, et al. Excessive sleepiness is predictive of cognitive decline in the elderly. Sleep 2012;35:1201-7.

36 Basta M, Simos P, Bertsias A, et al. Association between insomnia symptoms and cognitive impairment in the Cretan aging cohort. Eur Geriatr Med 2018;9:697-706.

37 Sabia S, Elbaz A, Britton A, et al. Alcohol consumption and cognitive decline in early old age. Neurology 2014;82:332-9.

38 Zissimopoulos JM, Barthold D, Brinton RD, et al. Sex and race differences in the association between statin use and the incidence of Alzheimer disease. JAMA Neurol 2017;74:225-32.

39 Schultz BG, Patten DK, Berlau DJ. The role of statins in both cognitive impairment and protection against dementia: a tale of two mechanisms. Trans/ Neurodegener 2018;7:5.

40 Wanamaker BL, Swiger KJ, Blumenthal RS, et al. Cholesterol, statins, and dementia: what the cardiologist should know. Clin Cardiol 2015;38:243-50.

41 Jick H, Zornberg GL, Jick SS, et al. Statins and the risk of dementia. Lancet 2000;356:1627-31.

42 Reitz C. Dyslipidemia and the risk of Alzheimer's disease. Curr Atheroscler Rep 2013;15:307.

43 van den Berg E, Kloppenborg RP, Kessels RPC, et al. Type 2 diabetes mellitus, hypertension, dyslipidemia and obesity: a systematic comparison of their impact on cognition. Biochim Biophys Acta 2009;1792:470-81.

44 Tyrovolas S, Bountziouka V, Papairakleous N, et al. Adherence to the Mediterranean diet is associated with lower prevalence of obesity among elderly people living in Mediterranean islands: the MEDIS study. Int J Food Sci Nutr 2009;60:137-50.

45 O'Keefe JH, Bybee KA, Lavie CJ. Alcohol and cardiovascular health: the razor-sharp double-edged sword. J Am Coll Cardiol 2007:50:1009-14.

46 Samii A, Nutt JG, Ransom BR. Parkinson's disease. Lancet 2004;363:1783-93

47 Booker A, Jacob LE, Rapp M, et al. Risk factors for dementia diagnosis in German primary care practices. Int Psychogeriatr 2016;28:1059-65.

48 Poblador-Plou B, Calderón-Larrañaga A, Marta-Moreno J, et al. Comorbidity of dementia: a cross-sectional study of primary care older patients. BMC Psychiatry 2014;14:84

49 Arevalo-Rodriguez I, Smailagic N, Roqué Figuls M, et al. Mini-Mental state examination (MMSE) for the detection of Alzheimer's disease and other dementias in people with mild cognitive impairment (MCl). Cochrane Database Syst Rev 2015;3:CD010783-CD. 